\title{
Effect of used rice straw of mushroom cultivation on growth performance and plasma metabolites in beef cattle
}

\author{
Sarker $D^{1}$, MRA Redoy ${ }^{1}$, NC Sarker ${ }^{2}$, MT Kamal $^{3}$ and M Al-Mamun ${ }^{1, *}$
}

${ }^{1}$ Department of Animal Nutrition, Bangladesh Agricultural University, Mymensingh 2202, Bangladesh; ${ }^{2}$ National Mushroom Development and Extension Centre, Department of Agricultural Extension, Savar-1340, Bangladesh; ${ }^{3}$ Department of Animal Science, Bangladesh Agricultural University, Mymensingh 2202, Bangladesh

\begin{abstract}
The present experiment was designed to know the feasibility of using rice straw used as bedding materials for mushroom cultivation as cattle feed and its effect on the growth performance and plasma metabolites in ten beef cattle (BW $73 \pm 7 \mathrm{~kg} ; 1$ year). The animals were divided into two groups and fed two diets using a crossover design for a period of 60 days each. Diet one was control diet (CL-diet) composed of rice straw, dhal grass, wheat bran, and mustard oil cake and in another diet $10 \%$ of rice straw of CL-diet was replaced by the rice straw used as bedding material for mushroom cultivation, which was considered as mushroom straw diet (URS-diet). In both the dietary treatments the animals were fed at 1.5 times of maintenance energy and protein requirement. The animals were weighed once a week throughout the experimental period, and the blood samples were collected on the day 60 of each experiment. The acid detergent fiber was slightly lower and neutral detergent fiber was slightly higher ( $P$ $<0.05)$ for URS-diet compared to CL-diet. The crude protein and crude ash contents were higher $(\mathrm{P}<$ 0.05 ) in URS-diet compared to CL-diet. Body weight gain was greater for URS-diet compared to CL-diet. Plasma concentration of glucose, and blood urea were comparable between dietary treatments. Plasma total cholesterol, triglyceride, HDL-C, and LDL-C were lower in URS-diet compared to CL-diet. It could be concluded that, the URS-diet could be fed to cattle without any adverse effect on growth and plasma lipid profile.
\end{abstract}

Key words: cattle, growth, plasma metabolites, spent mushroom substrate

Bangladesh Animal Husbandry Association. All rights reserved. Bang. J. Anim. Sci. 2016. 45 (3): $40-45$

\section{Introduction}

Livestock sector plays an important role in the rural economy of Bangladesh. It is well recognized as an integral component of farming systems. But this sector contributes only $30 \%$ of the agricultural sector compare to $55 \%$ from crop (Rashid, 1995). The biggest constraint behind this is identified as poor nutrition i.e. scarcity of feeds and fodder of livestock (Begum, 1992; Rashid, 1995). Due to high pressure on land for crop production for human consumption, farmers cannot spare land for fodder production for livestock feeding (Rashid, 1995). In this regard, Begum (1992) also stated that, while limitation of feed and fodder is seriously recognized, there is also equally important concern on how available feed resources are efficiently utilized. To overcome the scarcity of animal feed and to reduce feed cost it is necessary to find out the feasibility of using agro-industrial wastes.
In recent years, agro-industrial wastes e.g. poultry litter, cow dung, sugarcane bagasse, wood pulp, slaughter house waste etc. have attracted the attention of nutritionists for their economical and nutritional potentialities in the feeding of animals (El Sabban et al., 1970; Newton et al., 1977, Kumar et al., 1983). At present, synthetic antibiotic growth promoters are taken under banning policy and encouraged unconventional feedstuffs with bioactive components for logical importance in livestock farming. Mushroom, which is a fleshy saprophyte fungus, are found growing on damp rotten log of wood trunk of trees, decaying organic matter and in damp soil rich in organic substances. Edible mushroom are highly nutritious and can be compared with eggs, milk and meat. The content of essential amino acids in mushroom is high and close to the need of the human body (Oei, 2003). Mushroom is easily digestible and it has no cholesterol content. For these reasons mushroom

\footnotetext{
*Corresponding author: mamunshimu@yahoo.com
} 
cultivation in Bangladesh gradually gaining popularity. For mushroom cultivation straw is used extensively (Oei, 2003). Spent mushroom substrate is the organic material remaining after a crop of mushrooms has been harvested (Aamlid and Landschoot, 2007). So, spent mushroom substrate is a by-product of this culture system (Yohalem et al., 1996).

According to Langer et al. (1980) and Durrantet al. (1991) fungal cultivation resulted in considerable changes in the spent straw, remaining after mushroom harvesting, leading to increased crude protein and soluble cell wall content which might be more useful than the original straw when fed to ruminants. Rice straw is being used as bedding materials for mushroom (Agaricus bisporus) cultivation in Bangladesh. After harvesting the straw along with small particles of mushroom is either dumped of or burned as fuel for cooking. This waste material can be rich in microorganisms and extra-cellular enzymes (Ball and Jackson, 1995) and contain relatively high levels of nitrogen, potassium, phosphorus, calcium and trace elements, notably iron and silicon, (Langar et al., 1980; Burton et al., 1994) that may be used as animal feed. It might influence the growth performance and plasma metabolites in beef cattle. Use of this URS in animal feeding could be reduce the animal feed cost and at the same time could be minimized the environmental pollution caused through decomposition of the URS. Based on the above statement, the present experiment was undertaken to identify the effect of URS on growth performance and plasma metabolites in beef cattle.

\section{Materials and Methods}

\section{Animals, Diet and Management}

The experiment was conducted in the village of Fulbaria and Maltipur, Muktagasafor a period of 120 days. Ten (10) beef cattle aged 1 year with average live weight of $73 \pm 7 \mathrm{~kg}$ were reared in similar environmental conditions in village. The cattle were housed in individual pen within farmers shed and using a crossover design with two 60 days periods having five animals in each. Two dietary treatments, one was control diet (CLdiet) composed of rice straw, dhal grass, rice polish, wheat barn, and mustard oil cake and $10 \%$ of rice straw of CL-dietwas replaced by used rice straw in mushroom cultivation (URS-diet). In both the dietary treatments the animals were fed 1.5 times of maintenance energy and protein (NRC, 1985). The animals were weighed once a week throughout the experimental period using Shaeffer's law, and the blood samples were collected on day 60 of each experimental period.

Used rice straw in mushroom cultivation was collected in polythene bag from the farmers of Fulbaria and carried to Maltipur, Muktagacha.Normal rice straw was procured from local farmers. Feed ingredients such as dhal grass, rice polish, wheat bran, mustard oil cake, and common salt were purchased from local market of Mymensingh. The selected ten (10) farmers were advised to keep the animal separate from others; ensured vaccination and deworming program; cleaned, washed and disinfected the equipment with bleaching powder solution; ensured expected ration over the experimental period; recorded the temperature; ensured proper ventilation and observed clinical symptoms.

The roughages were provided equally two times (7.00 am and $4.00 \mathrm{pm}$ ) everyday whereas the concentrate mixture was provided in the morning. The clean and fresh water was provided ad libitum. The amount of feed offered daily and refusal feed at the end of each week was recorded. Feed intake, feed conversion efficiency and feed conversion ratio were calculated. The feed samples were collected in triplicate for the determination of proximate components. Blood samples were collected and centrifuged, then preserved it until further analysis.

\section{Proximate analysis}

The proximate components of feeds, leftovers and feces were analyzed according to AOAC (1995). The Acid Detergent Fiber (ADF) and Neutral Detergent Fiber (NDF) analysis was performed according to Mertens (2002). Plasma glucose level was estimated by enzymatic Glucose oxidase method' (GOD method). Plasma cholesterol is determined by Cholesteroloxidase method (CHOD/POD method). Plasma triglycerides were estimated by the commercial available reagent kit (Atlass Co. Ltd, Japan). HDL, 
LDL and VLDL were determined using crescent diagnostics cholesterol test kit, Saudi Arabia (Cat No. CS 603)

\section{Statistical analysis}

At first the raw data were organized using computer Excel program and then analyzed using SPSS Statistics (originally, Statistical Package for the Social Sciences, later modified to read Statistical Product and Service Solutions) for oneway analysis of variance (ANOVA). Mean value, Standard error, and P-values were calculated from it. $P$-values less than $0.05(P<0.05)$ and less than $0.01 \quad(P<0.01)$ were considered to be statistically significant.

\section{Results and Discussion}

Results and discussion on body weight change, nutrient digestibility and plasma parameters of cattle for URS-diet and CL-diet are presented in different subheadings.

\section{Body weight changes}

The body weight changes did not differ significantly between dietary treatments (Figure 1 ). But the body weight gain numerically tended to be higher $(P=0.063)$ in URS-diet group than CL-diet group $(P=0.055)$.

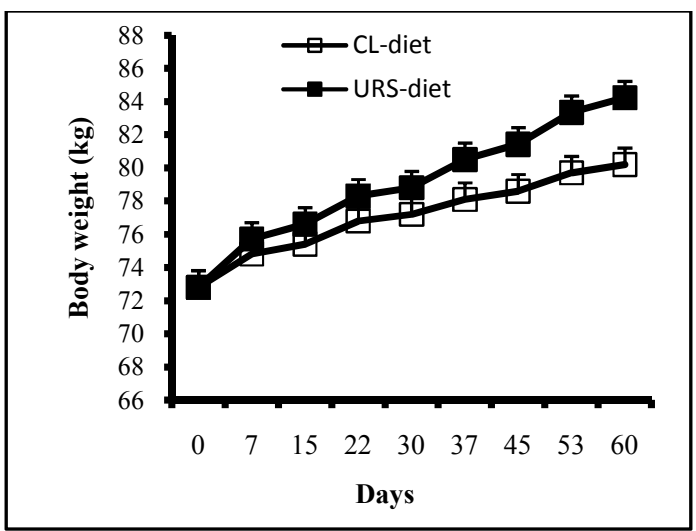

Figure 1. Graphically shown weekly body weight changes (kg/animal) of beef cattle under two dietary treatments; Solid Square indicates CL-diet and open square indicates URS-diet.

Huck et al. (2000) reported that the weight gain of feedlot beef cattle with added direct-fed microbes (DFM) increased by 2.5 to $3.0 \%$. (Galyeanet al., 2000) also reported that dietary addition of DFM increased the body weight of feedlot cattle. It is believed that feeding mushroom-straw rich diet favorably affected the growth of Hanwoo steers because it functions as sources of roughage as well as DFM.

Table 1: Effect of used rice straw (URS) in mushroom cultivation (URS-diet) on nutrient digestibility of beef cattle

\begin{tabular}{lcccc}
\hline \multirow{2}{*}{ Parameters } & \multicolumn{2}{c}{ Treatments* } & \multirow{2}{*}{ SEM } & P-value \\
\cline { 2 - 3 } & CL- diet & URS- diet & & \\
\hline DM digestibility (\%) & $46.91 \pm 0.77$ & $41.81 \pm 0.67$ & 0.61 & 0.19 \\
CP digestibility (\%) & $61.11 \pm 2.33$ & $65.47 \pm 2.31$ & 1.59 & 0.001 \\
ADF digestibility (\%) & $47.24 \pm 3.16$ & $45.66 \pm 2.19$ & 0.78 & 0.91 \\
NDF digestibility (\%) & $49.37 \pm 1.37$ & $52.05 \pm 4.60$ & 2.43 & 0.33 \\
EE digestibility (\%) & $30.45 \pm 1.40$ & $34.92 \pm 1.59$ & 2.73 & 0.001 \\
\hline
\end{tabular}

*CL-diet, rice straw, dhal grass, rice polish, wheat barn, and mustard oil cake; URS-diet, $10 \%$ of rice straw of $\mathrm{CL}$-dietwas replaced by used rice straw in mushroom cultivation;Values indicate Mean $\pm \mathrm{SE}$; standard error; SEM, standard errors of mean; DM, dry matter; CP, crude protein; ADF, acid detergent fiber; NDF, neutral detergent fiber; $\mathrm{EE}$, ether extract. 


\section{Nutrient digestibility}

Table 1 shows the nutrient digestibility of URSdiet group and CL-diet group. Dry matter (DM) digestibility was slightly lower and ether extract (EE) digestibility was significantly higher $(P=0.17$ and $P=0.001$, respectively) for URS-diet than CLdiet. Crude protein (CP) digestibility tended to be higher $(P=0.001)$ in URS-diet. Similarly ADF was slightly lower and NDF digestibility tended to be higher $(P=0.91$ and $P=0.33$, respectively) for URS-diet than CL-diet. The ash digestibility remained unchanged $(P=0.23)$ between URS-diet and CL-diet.

In current study, the feed consumption rate of growing beef cattle was higher in URS-diet group than CL-diet group. It was observed that, URSdiet was highly palatable for beef cattle. Silvana et al. (2006) and Adamovic et al., (1998) reported that bio-degradation of straw with Pleurotusostreatus increased its nutritional value and digestibility in ruminant diets. Kumar (1991) observed that, herbal formulations as growth promoters have shown encouraging results on feed intake in poultry birds. In the present study, dry matter (DM \%) digestibility was slightly lower and ether extract (EE \%) digestibility was significantly higher in URS-diet group than CLdiet group. According to Fazaeli et al (2006), inclusion of mushroom-straw diet up to $20 \%$ of the diet did not affect the digestibility of nutrients, which may reflect the absence of a negative effect of dietary inclusion of mushroomstraw diet. On the other hand $40 \%$ mushroom- straw does not decrease rumen microbial fermentative activity and affect digestibility in a positive manner (Choi et al. 2010). Probably, the use of higher spent mushroom straw in ration will be given better output in term of productivity of animal.

Numerous studies have shown that the bioactive components of mushroom have various beneficial effects including immunomodulatory, hypocholesterolemic, and anti-tumor influences on animals and humans (Yoshioka et al., 1985; Fukushima et al., 2000; Lull et al., 2005). In this current study, crude protein (CP) and neutral detergent fiber (NDF) digestibility were numerically higher, but acid detergent fiber (ADF) digestibility found slightly lower in URS-diet group than CL-diet. Crude ash content was also numerically higher in URS-diet than CL-diet in this current study.

\section{Changes of plasma parameters}

There were no significant effects on the plasma parameters, which are shown in Table- 2. Plasma glucose concentrations $(P=0.85)$ did not differ significantly. It was found that numerical value of plasma glucose was higher for URS-diet than CLdiet. Total cholesterol, triglycerides, LDL-C and HDL-C did not differ significantly but numerically lower $(\mathrm{P}=0.098, \mathrm{P}=0.36, \mathrm{P}=0.12$ and $\mathrm{P}=0.20$, respectively) for URS-diet than $\mathrm{CL}$-diet. Blood urea nitrogen were numerically lower $(P=0.61)$ for URS-diet than CL-diet.

Table 2. Effect of used rice straw (URS) of mushroom cultivation (URS-diet) on plasma parameters of beef cattle

\begin{tabular}{|c|c|c|c|c|}
\hline \multirow{2}{*}{ Parameters } & \multicolumn{2}{|c|}{ Treatments* } & \multirow{2}{*}{ SEM } & \multirow{2}{*}{ P-value } \\
\hline & CL-diet & URS-diet & & \\
\hline Glucose (mmol/L) & 5.6 & 5.7 & 0.2 & 0.85 \\
\hline T Cholesterol (mg/dL) & 176.3 & 133.8 & 13.5 & 0.098 \\
\hline Triglyceride (mg/dL) & 41.6 & 36.5 & 2.8 & 0.36 \\
\hline HDL-C (mg/dL) & 7.2 & 4.8 & 0.9 & 0.20 \\
\hline LDL-C (mg/dL) & 160.8 & 121.7 & 13.1 & 0.12 \\
\hline BUN (mg/dL) & 2.2 & 2.0 & 0.2 & 0.61 \\
\hline
\end{tabular}

*CL-diet, rice straw, dhal grass, rice polish, wheat barn, and mustard oil cake; URS-diet, $10 \%$ of rice straw of $\mathrm{CL}$-dietwas replaced by used rice straw in mushroom cultivation, Values indicates; \# SEM, Standard Errors of mean; HDL-C, High density lipoprotein; LDL-C, Low density lipoprotein; BUN, Blood urea nitrogen. 


\section{Spent mushroom substrate for beef cattle}

Glucose metabolism is influenced by nutritional and physiological conditions of animals (Buckley et al., 1982) and reduced during heat exposure (Sano et al., 1983). Blood glucose is one of the most common metabolites used to assess the energy status of cattle (Ndlovu et al., 2007). Park et al. (2012) studied that spent mushroom substrate (SMS) had higher BUN and glucose concentrations, and these results may be attributed to higher nitrogen (N) and energy consumption due to increased feed intake of $10 \%$ (15\% SMS group) and $17 \%$ (20\% SMS group), as compared to the control group. In the current study, plasma glucose concentrations did not differ significantly. It was found that numerical value of plasma glucose was higher for URS-diet than CL-diet. Cholesterol contains triglycerides and low-density lipoprotein (LDL-C), very lowdensity lipoprotein (VLDL-C) and high-density lipoprotein (HDL-C).

In this experiment, cholesterol, triglycerides, HDL-C and LDL-C were numerically lower for URS-diet than CL-diet in every case. HDL-C is tested to determine risk of developing heart disease (Thomas et al. 1997). HDL-C is helpful for recovery of cardiovascular diseases also. The addition of mushrooms affected serum triglyceride and cholesterol concentrations and effectively prevented the progress of hypercholesterolemia and cholesterol accumulation in liver induced by a high cholesterol diet in rats (Bobek et al., 1995;

\section{References}

Aamlid TS and PJ Landschoot (2007). Effect of spent mushroom substrate on seed germination of cool-season turf grasses. HortScience 42(1): 161-167.

Adamovic M, G Grubic, I Milenkovic, R Jovanovic, R Protic, L Sretenovic and L Stoicevic (1998). The biodegradation of wheat straw by Pleurotusostreatusmushrooms and its use in cattle feeding. Animal Feed Science Technology 71: 357-362.

AOAC (1995). Official Methods of Analysis (14th ed.). Association of official Analytical Chemists. Washington, DC, USA.

Ball AS and AM Jackson (1995). The recovery of lignocellulose degrading enzymes from spent mushroom compost. Bio Res. Technol. 54:311314

Begum J (1992). Effect of replacing concentrate mixture by different levels of tea waste on the performances of growing calves. MS thesis,
Fukushima et al., 2001). The percentage of URS replacement was not sufficient for altering significant variation between CL-diet and URSdiet groups at all cases. Probably, higher percentage of URS-diet supplement will get positive output in URS-diet group. In ruminants, urea can be influenced by quantity of dietary protein, level of feed intake, and protein degradability in the rumen (Karnezos et al., 1994). Blood urea nitrogen level was found statistically non-significant in the current study. The BUN test is used to evaluate kidney function and to monitor the effectiveness of dialysis and other treatments related to kidney disease or damage. Though Urea level of blood showed no significant difference, numerically lower value in case of URS-diet found during the study period.

\section{Conclusion}

The used rice straw diet (URS-diet) showed variation for body weight change, nutrient digestibility and plasma parameters. It is revealed that under present experimental conditions, the URS-diet could be fed to cattle without any adverse effect on growth performance and plasma lipid profiles. It can also be concluded that used rice straw of mushroom cultivation is a good choice for cattle feed establishment.

Department of Animal Nutrition, Bangladesh Agricultural University.

Bobek P, O Ozdin and M Mikus (1995). Dietary oyster mushroom (Pleurotusostreatus) accelerates plasma cholesterol turnover in hypercholesterolemia rats. Physiological Research 44: 287-291.

Buckley B, JH Herbein and JW Young (1982). Glucose kinetics in lactating and non-lactating dairy goats. Journal of Dairy Science65: 371384

Burton KS, JBV Hammond and T Minamide (1994). Protease activity in Agaricusbisporus during periodic fruiting (flushing) and sporophore development. Current Microbiology 28(5): 275278.

Choi N, YK Oh, WM Lee, CW Choi, KH Kim, SK Hong, SC Lee, YJ Seol and WS Kwak (2010). Effects of spent mushroom substrates supplementation on rumen fermentation and blood metabolites in 
hanwoo steers. Asian-Australian Journal of Animal Science 23(12): 1608 - 1613.

Durrant AJ, DA Wood and RB Cain (1991). Lignocellulose biodegradation by Agaricusbisporus during solid substrate fermentation. Journal of General Microbiology137: 751-755.

El Sabban FF, JW Bratzler,TA Long, DEH Frear and RF Gentry (1970). Value of processed poultry waste as a feed for ruminants. Journal of Animal Science 31: 107-111

Fazaeli H and MAR Talebian (2006). Spent wheat straw compost of Agaricusbisporusmushroom as ruminant feed. Asian-Australian Journal of Animal Science 19: 845-851.

Fukushima M, Y Nakano, $Y$ Morii, T Ohashi, $Y$ Fujiwara and K Sonoyama (2000). Hepatic LDL receptor mRNA in rats is increased by dietary mushroom (Agraicusbisporous) fibre and sugar beet fibre. Journal of Nutrition130:2151-2156.

Fukushima M, T Ohashi, Y Fujiwara, K Sonoyama and M Nakano (2001). Cholesterol-lowering effects of maltase (Grifolafrondosa) fibre, shiitake (Lentinusedodes) fibre, and enokitake (Flammulinavelutipes) fibre in rats. Experimental Biological Medical (Maywood) 226: 758-765.

Galyean ML, GA Nunnery, PJ Defoor, GB Salyer and $\mathrm{CH}$ Parsons (2000). Effects of live cultures of Lactobacillus acidophilus (strains 45 and 51) and Propioni bacterium freudenreichii PF-24 on performance and carcass characteristics of finishing beef steers. Burnett Centre Internet Progress Report No: 8.

Huck GL, KK Kreikemeier and GA Ducharme (2000). Effects of feeding two microbial additives in sequence on growth performance and carcass characteristics of finishing heifers Kansas. Report of Progress KSU Agric. Exp. St. and Coop. Ext. Service at State University Cattlemen's Day. USA. pp. 32-34.

Karnezos TP, AG Matches, RL Preston and CP Brown (1994). Corn supplementation of lambs grazing alfalfa. Journal of Animal Science72: 783-789.

Kumar N, UB Singh and MY Khan (1983). Effect of feeding ammoniated bago-molasses on live weight gain and nutrient utilization in crossbred calves. Indian Journal of Animal Science 53 1177-1180.

Kumar OM (1991). Effect of Liv-52® syrup on broiler performance in North Eastern region. Indian Journal of Poultry Science 22: 37-38.
Langar PN, JP Sehgal and HS Garcha (1980). Chemical changes in wheat and paddy straws after fungal cultivation. Indian Journal of Animal Science 50(11): 942-946.

Lull C, HJ Wichers and HFJ Savelkoul (2005). Antiinflammatory and immunomodulating properties of fungal metabolites. Mediators Inflammation 85: 63-80.

Ndlovu T, M Chimonyo, AI Okoh, V Duchene, K Dzama and JG Raats (2007). Assessing the nutritional status of beef cattle: current practices and future prospects. African Journal of Biotechnology 6: 2727-2734.

Newton GLPR, RJ Utely, Ritter and WC Mecormic (1977). Performance of beef cattle fed wastage and digestibility of wastage and dried waste diets. Journal of Animal Science 44447

Oei P (2003). Mushroom cultivation, appropriate technology for mushroom growers. Backhugs Publishers, Leiden.The Netherlands.

Park JH, SW Kim, YJ Do, H Kim, YG Ko, BS Yang, D Shin and YM Cho (2012). Spent mushroom substrate influences elk (CervusElaphus Canadensis) hematological and serum biochemical parameters. Asian-Australian Journal of Animal Science 25(3): 320-324.

Rashid (1995). Effect of replacing til oil cake by poultry excreta on growth and nutrient utilization in growing bull calves. MS thesis, Department of Animal Nutrition, Bangladesh Agricultural University.

Sano H, K Takashashi, K Ambo and T Tsuda (1983). Turnover and oxidation rates of blood glucose and heat production in sheep exposed to heat. Journal of Dairy Science66: 856-861.

Silvana A, MJ Pianzzola, M Soubes and MP Cerdeiras (2006). Biodegradation of agroindustrial wastes by Pleurotusspp. For its use as ruminant feed. Electronic Journal Biotechnology 9: 215-220.

Thomas CL, Editor (1997). Taber's CyclopedicMedical Dictionary. FA Davis Company, Philadelphia, PA [18th Edition].

Yohalem DS, EV Nordheim and JH Andrews (1996). The effect of water extracts of spent mushroom compost on apple scab in the field. Phytopathology 24: 914- 922.

Yoshioka Y, R Tabeta, H Saito, N Uehara and F Fukuoka (1985). Antitumor polysaccharides from P.ostreatus(Fr.) Quel. Isolation and structure of a beta-gulcan. Carbohydrate Research140: 93-100. 